\title{
Cerebral Venous Thrombosis in a Case of P. Vivax Malaria
}

\section{Kunal Lala*, Divya Lala, Anannya Mukherji and Santwana Chandralkar}

Department of Medicine, Dr. D Y Patil Medical College, Navi Mumbai, Maharashtra, India

\begin{abstract}
Cerebral Venous Thrombosis (CVT) is relatively an uncommon manifestation in adults with Malaria. CVT is more often seen in patients with Falciparum malaria. Here we present a rare case of a 31-year-old male with Vivax malaria, who developed diplopia secondary to CVT. His treatment involved anticoagulation, analgesics as well as treatment of malaria.
\end{abstract}

\section{Case Report}

A 31-year-old previously healthy male presented himself to a local physician with complaints of high grade fever and headache for 2 days. The local physician treated the patient with oral anti-malarials after his $\mathrm{CBC}$ revealed $P$. vivax malaria. The patient was referred to our hospital because the fever and headache failed to subside and he developed sudden onset of diplopia. The fever was high grade intermittent type, associated with chills. There was no history of seizures, breathlessness or diarrhoea. No past history of similar episode, nor any family history of it. There was no history of alcohol, tobacco or any other drug abuse. On examination, his pulse was $74 / \mathrm{min}$, regular; his BP was $124 / 70 \mathrm{~mm}$ $\mathrm{Hg}$ and his abdominal examination revealed mild splenomegaly. On CNS examination the patient was conscious, oriented and neck rigidity was absent. Bilateral lateral rectus muscle weakness was noted.

Pupils were normal in size and reacting bilaterally to light. Fundus examination revealed Grade 2 Papilledema. There was no motor or sensory deficit. Reflexes and Plantar response were normal. His blood sample results showed Hb-15 gm/dl, WBC $8000 / \mathrm{mm}^{3}$, Platelet- 328 thousand $/ \mathrm{mm}^{3}$. Ring forms of $P$. vivax were present, Malaria antigen test was positive for Non-falciparum malaria, ESR 23, renal function and Liver functions were within normal limits. Lipid profile was within normal limits. Prothrombin time patient-13 sec, control-11 sec. MRI of brain revealed early subacute thrombosis of the portion of superior sagittal sinus, confluence of sinuses, right sigmoid and transverse sinuses. MR venogram was planned. Further tests could not be performed as the patient refused anymore blood or radiological investigations.

The patient was given Inj. Mannitol $100 \mathrm{ml}$ stat and thrice a day along with Inj. Artesunate, Cap. Doxycycline, Tab. Diclofenac, Inj. Heparin. On the next day of treatment the patient started improving symptomatically. Tab. Diclofenac (Analgesic) was stopped, he was afebrile by day 3 , headache was gone and there was subjective improvement in his diplopia. Oral anticoagulant was advised and the patient was discharged on request, subsequently patient was lost to follow-up.

\section{Discussion}

Severe complications of malaria has been traditionally attributed to falciparum malaria or mixed infections. In recent times many cases of unusual complications has been increasingly associated to isolated infections with $P$. vivax malaria. Cerebral venous thrombosis is a rare complication associated with falciparum malaria. We are reporting a case of $P$. vivax malaria presenting with the same complication. The pathogenesis of Cerebral Venous thrombosis in this case remains elusive.
P. vivax malaria can cause both sequestration-related and non sequestration-related complications of severe malaria [1]. Clinicolaboratory profile of six patient of $P$. vivax cerebral malaria was studied by Sachdev and Mohan [2] which varied in presentation from encephalopathy, convulsions, coma to focal neurological deficit. The mechanism of cerebral venous thrombosis in a case of severe malaria remains unclear and is probably multifactorial, a hypercoaguable state induced by severe malaria may be responsible for the condition as proposed by Krishnan et al. [3]. Tissue factor expression by the endothelium and amplification of coagulation cascade by infected red blood cells may be associated with a procoagulant state in severe malaria according to work by Ivo MB Francischetti and others [4-6].

\section{Conclusion}

$P$. vivax malaria is showing increasing tendency to cause complications which is not known to be associated with it, as reported from various malaria endemic area. Further studies are required to know the exact mechanism causing such a phenomenon. Clinicians must be aware of such unusual presentations which will help them reduce the morbidity and mortality associated with the disease.

\section{References}

1. Kochar DK, Saxena V, Singh N, Kochar SK, Kumar SV, et al. (2005) Plasmodium vivax malaria. Emerg Infect Dis 11: 132-134

2. Sachdev HS, Mohan M (1985) Vivax cerebral malaria. J Trop Pediatr 31: 213 215.

3. Krishnan A, Karnad DR, Limaye U, Siddharth W (2004) Cerebral venous and dural sinus thrombosis in severe falciparum malaria. J Infect 48: 86-90.

4. Francischetti IM, Seydel KB, Monteiro RQ, Whitten RO, Erexson CR, et al (2007) Plasmodium falciparum-infected erythrocytes induce tissue factor expression in endothelial cells and support the assembly of multimolecular coagulation complexes. J Thromb Haemost 5: 155-165.

5. Oliveira-Ferreira J, Lacerda MV, Brasil P, Ladislau JL, Tauil PL, et al. (2010) Malaria in Brazil: an overview. Malar J 9: 115.

6. Limaye CS, Londhey VA, Nabar ST (2012) The Study of Complications of Vivax Malaria in comparison with Falciparum Malaria in Mumbai. JAPI 60.

*Corresponding author: Kunal Lala, Department of Medicine, Dr. D Y Patil Medical College, Navi Mumbai, Maharashtra, India, Tel: +919830828294; E-mail: kunal_lala2000@yahoo.com

Received May 06, 2013; Accepted May 23, 2013; Published May 25, 2013

Citation: Lala K, Lala D, Mukherji A, Chandralkar S (2013) Cerebral Venous Thrombosis in a Case of P. Vivax Malaria. J Trop Dis 1: 105 doi:10.4172/329-891X.1000105

Copyright: (c) 2013 Lala K, et al. This is an open-access article distributed unde the terms of the Creative Commons Attribution License, which permits unrestricted use, distribution, and reproduction in any medium, provided the original author and source are credited. 